\title{
Enhanced Antioxidant Enzymes Are Associated with Reduced Hydrogen Peroxide in Barley Roots under Saline Stress
}

\author{
Sang Yong Kim ${ }^{\ddagger}$ Jung-Hyun Lim, Myoung Ryoul Park, Young Jin Kim, Tae Il Park \\ Yong Won Seo ${ }^{\S}$, Kyeong Gu Choi and Song Joong Yun* \\ ${ }^{\dagger}$ Division of Biological Resources Sciences, and Institute of Agricultural Science and Technology, Chonbuk Natl University, \\ Chonju 561-756, Korea \\ Honam Agricultural Research Institute, National Institute of Crop Science, Iksan 570-080, Korea \\ ${ }^{\S}$ Division of Biotechnology and Genetic Engineering, Korea University, Seoul 136-071, Korea
}

Received 5 October 2004, Accepted 10 January 2005

\begin{abstract}
Antioxidant enzymes are related to the resistance to various abiotic stresses including salinity. Barley is relatively tolerant to saline stress among crop plants, but little information is available on barley antioxidant enzymes under salinity stress. We investigated temporal and spatial responses of activities and isoform profiles of superoxide dismutase (SOD), catalase (CAT), ascorbate peroxidase (APX), non-specific peroxidase (POX), and glutathione reductase (GR) to saline stress in barley seedlings treated with $200 \mathrm{mM} \mathrm{NaCl}$ for $0,1,2,5$ days, respectively. In the control plant, hydrogen peroxide content was about 2-fold higher in the root than in the shoot. Under saline stress, hydrogen peroxide content was decreased drastically by $70 \%$ at $2 \mathrm{~d}$ after $\mathrm{NaCl}$ treatment (DAT) in the root. In the leaf, however, the content was remained unchanged by 2 DAT and increased about $14 \%$ at 5 DAT. In general, the activities of antioxidant enzymes were increased in the root and shoot under saline stress. But the increase was more significant and consistent in the root. The activities of SOD, CAT, APX, POX, and GR were increased significantly in the root within 1 DAT, and various elevated levels were maintained by 5 DAT. Among the antioxidant enzymes, CAT activity was increased the most drastically. The significant increase in the activities of SOD, CAT, APX, POX, and GR in the NaCl-stressed barley root was highly correlated with the increased expression of the constitutive isoforms as well as the induced ones. The hydrogen peroxide content in the root
\end{abstract}

Present address: Division of Specimen and Genetic Resources, Korea National Arboretum, Pocheon 487-821, Korea

*To whom correspondence should be addressed.

Tel: 82-63-270-2508; Fax: 82-63-270-2640

E-mail: sjyun@moak.chonbuk.ac.kr was most highly correlated with the CAT activity, indicating an increased role of CAT in hydrogen peroxide detoxification under salinity stress. In addition, the results suggest the significance of temporal and spatial regulation of each antioxidant isoform in determining the competence of the antioxidant capacity under saline stress.

Keywords: Antioxidant enzymes, Barley, Hydrogen peroxide, Salt stress

\section{Introduction}

Increased use of fertile agricultural lands for human activities other than crop production pushes crop cultivation to less productive lands, including saline areas. Plants in saline areas are easily exposed to multiple abiotic stresses. Among these stresses, high salinity is the most severe factor limiting plant growth in the areas.

It is well documented that abiotic stresses exert at least in part of their effects by causing oxidative damage (Smimoff, 1995). Oxidative damages are caused by reactive oxygen species (ROS) and excess amounts of ROS are harmful to many cellular components, including membrane lipids. ROS cause peroxidation of polyunsaturated fatty acids in the membranes (Smirnoff, 1995). Production of ROS is increased under saline conditions (Greenway and Munns, 1980; Hasegawa et al., 2000) and ROS-mediated membrane damage has been demonstrated to be a major cause of the cellular toxicity by salinity in rice, tomato and citrus (Gueta-Dahan et al., 1997; Dionisio-Sese and Tobita, 1998; Mittova et al., 2004).

However, ROS are inevitable byproducts from the essential aerobic metabolisms, and they need to be maintained under sublethal levels for normal plant growth. Hence, plants are 
equipped with an array of enzymatic and non-enzymatic antioxidant molecules to alleviate cellular damage caused by ROS (Foyer and Noctor, 2000; Apel and Hirt, 2004). Multiple antioxidant enzymes systems are involved in the enzymatic scavenging of ROS. Superoxide dismutases (SOD, EC 1.15.1.1) react with the superoxide radical to produce $\mathrm{H}_{2} \mathrm{O}_{2}$. Hydrogen peroxide is scavenged by catalases (CAT, EC 1.11.1.6) and peroxidases (POX, EC 1.11.1.7). Among peroxidases, ascorbate peroxidases (APX, EC 1.11.1.11) and glutathione peroxidase (GPX, EC 1.11.1.9) which use ascorbate and glutathione as electron donors, respectively, are well known for their role in $\mathrm{H}_{2} \mathrm{O}_{2}$ detoxification in plants. Glutathione reductase (GR, EC 1.6.4.2) is responsible for the reduction of oxidized glutathione for the chain reactions of scavenging $\mathrm{H}_{2} \mathrm{O}_{2}$ by APX and GPX to be completed and continued (Mittler, 2002; Apel and Hirt, 2004).

A large body of evidence has shown that the antioxidant enzyme systems are altered under abiotic stresses, including salinity. The quantitative and qualitative aspects of changes are often related to the levels of resistance to salinity. In rice, the salt-tolerant varieties have higher SOD activity and lower lipid peroxidation than the salt-sensitive varieties (DionisioSese and Tobita, 1998). In tomato and citrus, salt-tolerance is attributed to the increased activities of SOD, APX, and CAT (Gueta-Dahan et al., 1997; Mittova et al., 2004). Further supporting evidence on the involvement of antioxidant enzymes in salt tolerance has been provided by transgenic plants with a reduced or an increased expression of antioxidant enzymes. The antisense plants with reduced CAT activity are hypersensitive to salt and other oxidative stresses (Willekens et al., 1997). Increased protection to salt stress has been demonstrated by the overexpression of cytosolic APX (Torsethaugen et al., 1997). Enhanced oxidative stress tolerance was also observed in the plants overexpressing $\mathrm{Fe}$ SOD (Van Camp et al., 1996).

Barley is relatively tolerant to salt stress compared to other crop plants and considered to be used at the early stage of cultivation trial of newly acclimated tideland. Even though much supporting evidence on the role of antioxidant enzymes in salt tolerance is available, there is little information on barley antioxidant enzymes under salinity stress. Here, we report that the increases in the expression of activities and isoforms of SOD, CAT, APX, POX and GR were associated with decrease in hydrogen peroxide in the salt-stressed root.

\section{Materials and Methods}

Chemicals and plant materials All chemicals and enzymes were purchased from Sigma (St. Louis, USA), unless otherwise indicated. Barley seeds (Hordeum vulgare cv. Saessalbori) were surface-sterilized in $0.5 \%$ sodium hypochloride solution for $20 \mathrm{~min}$ and germinated at $20^{\circ} \mathrm{C}$. Uniform seedlings were transferred to and grown in a hydrophonic system as previously described (Park et al., 2003). At the $3^{\text {rd }}$ leaf stage, the seedlings were subjected to treatment with $200 \mathrm{mM} \mathrm{NaCl}$ for $0,1,3$, and $5 \mathrm{~d}$, respectively. Samples of roots and shoots were collected at the treatment intervals, ground into fine powder under liquid nitrogen, and used for enzyme assays.

Hydrogen peroxide assay Hydrogen peroxide content was determined by measuring the absorbance of titanium-hydroperoxide complex (Mukherjee and Choudhari, 1983). The acetone extract of the tissue was reacted with titanium reagent and ammonium to form hydroperoxide-titanium complex. The complex was dissolved in 1 $M$ sulfuric acid and absorbance of the supernatant was measured at $415 \mathrm{~nm}$ against blank. Concentration of hydrogen peroxide was determined using the standard curve plotted with known concentration of hydrogen peroxide.

Enzyme activity assay and isozyme analysis Essentially the same protein extraction and electrophoresis methods were used as described (Baek et al., 2000; Choi et al., 2004). Total cellular extracts, prepared at $4^{\circ} \mathrm{C}$ were used for activity assays and isozyme analysis for each antioxidant enzyme. The activities of APX, POX, CAT, GR, and SOD were determined spectrophotometrically. APX activity was determined following the oxidation of ascorbate to dehydroascorbate, as described by Nakano and Asada (1981). Nonspecific POX activity was determined by measuring peroxidation of hydrogen peroxide with guaiacol as an electron donor (Chance and Maehly, 1955). APX isoforms were detected on nondenaturing polyacrylamide gels (7\% acrylamide, $3 \%$ bis-acrylamide) containing $10 \%$ glycerol according to Mittler and Zilinskas (1993). POX isoforms were detected on ultrathin-layer IEF gels according to Wendel (1987). CAT activity was assayed by measuring the conversion rate of hydrogen peroxide to water and oxygen molecules (Beers and Sizer, 1952). CAT isoforms were detected on nondenaturing polyacrylamide gels (7\% acrylamide, 3\% bisacrylamide) containing $10 \%$ glycerol as described by Woodbury et al. (1971). Dithiotreitol (60 mM) was added in the sample loading buffer for CAT isoform detection. GR activity was determined by measuring the reduction kinetics of oxidized glutathione (OKane $e t$ al., 1996). GR isoforms were detected on nondenaturing polyacrylamide gels (7\% acrylamide, 3\% bis-acrylamide) containing 10\% glycerol according to Anderson et al. (1995). SOD activity was assayed by determining the inhibition rate of nitroblue tetrazolium reduction with xanthine oxidase as a hydrogen peroxide generating agent (Obeley and Spitz, 1984; Kang, 2004). SOD isoforms were detected on nondenaturing polyacrylamide gels $(10 \%$ acrylamide, 3\% bis-acrylamide) as described by Beauchamp and Fridovich (1971). The protein contents of the enzyme extracts were determined by using the Bradford (1979) method. Assays were conducted for the three-replicated treatments and the enzyme activity data were analyzed using the SAS program (SAS Institute Inc., Cary, USA).

\section{Results}

Hydrogen peroxide content Hydrogen peroxide content was 2.2-fold higher in the root than in the shoot of unstressed plants as $5.6 \mu \mathrm{mol} / \mathrm{g}$ fresh weight. In the root, the content was 


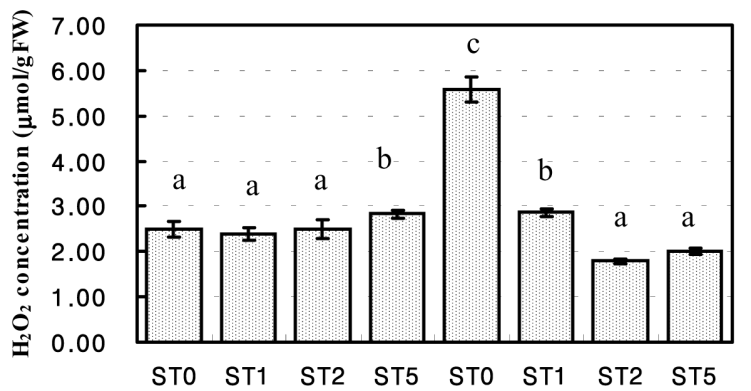

Fig. 1. The hydrogen peroxidase content in the $\mathrm{NaCl}$-treated barley shoots (ST) and roots (RT). Barley seedlings at the $3^{\text {rd }}$ leaf stage were treated with $200 \mathrm{mM} \mathrm{NaCl}$ for $0,1,2$ and $5 \mathrm{~d}$, respectively. The treatments indicated by the same letters are not significantly different $(p \leq 0.05)$ within the tissue.

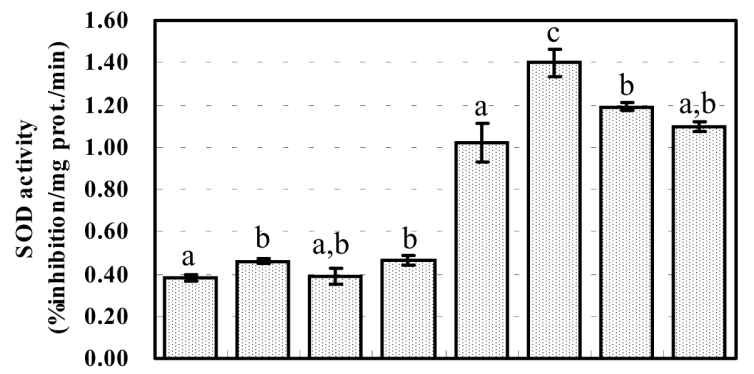

$\begin{array}{llllllll}\text { ST0 } & \text { ST1 } & \text { ST2 } & \text { ST5 } & \text { RT0 } & \text { RT1 } & \text { RT2 } & \text { RT5 }\end{array}$

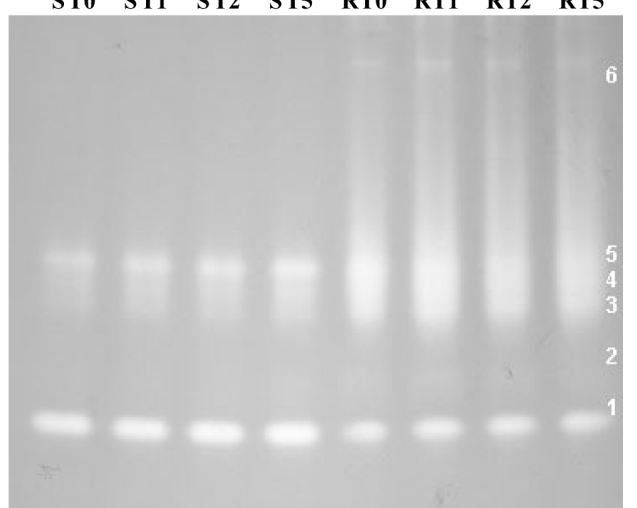

Fig. 2. The responses of SOD activities and isoforms in the NaCl-treated barley shoots (ST) and roots (RT). Barley seedlings at the $3^{\text {rd }}$ leaf stage were treated with $200 \mathrm{mM} \mathrm{NaCl}$ for $0,1,2$ and $5 \mathrm{~d}$, respectively. The treatments indicated by the same letters are not significantly different $(p \leq 0.05)$ within the tissue. SOD isoforms were detected on nondenaturing polyacrylamide gels (10\% acrylamide, 3\% bis-acrylamide) as described by Beauchamp and Fridovich (1971).

decreased to about 50 and $30 \%$ of the control by 1 and 2 days after $200 \mathrm{mM} \mathrm{NaCl}$ treatment (DAT). However, the content in the shoot was remained unchanged by 2 DAT, and increased $12 \%$ in 5 DAT (Fig. 1). Hydrogen peroxide content is generally increased in the leaf of salt-stressed plant (Sairam $e t$ al., 2002; Fedina et al., 2003) showing little association with salt-tolerance. However, hydrogen peroxide content in the root is often related to the salt tolerance. Decreased hydrogen

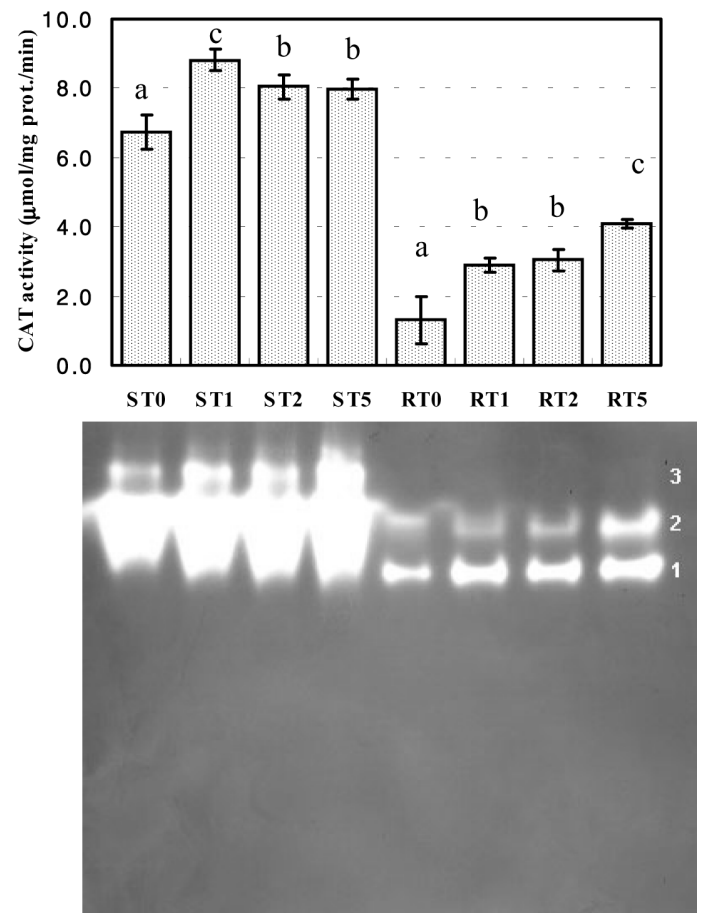

Fig. 3. The responses of CAT activities and isoforms in the $\mathrm{NaCl}$-treated barley shoots (ST) and roots (RT). Barley seedlings at the $3^{\text {rd }}$ leaf stage were treated with $200 \mathrm{mM} \mathrm{NaCl}$ for $0,1,2$ and $5 \mathrm{~d}$, respectively. The treatments indicated by the same letters are not significantly different $(p \leq 0.05)$ within the tissue. CAT isoforms were detected on nondenaturing polyacrylamide gels (7\% acrylamide, 3\% bis-acrylamide) containing 10\% glycerol as described by Woodbury et al. (1971).

peroxide content in the root coincides with salt tolerance in rice (Dionisio-Sese and Tobita, 1998) and tomato (Mittova et al., 2004).

Superoxide dismutase The specific SOD activity was increased in the root and shoot under salt stress, but its response patterns were variable in the tissues. In the root, SOD activity was increased the most, by about $37 \% 1$ DAT, but the increase was reduced gradually by 5 DAT. In the shoot, the activity was increased by about $21 \%$ at 1 DAT and the increase alternated at variable levels. The activity in the root was about three-times higher than that in the shoot (Fig. 2).

Increase in enzyme activity coincided with a variable increase in the individual isoform expression. At least five or six isoforms were detected in the shoot and root with SOD1 and SOD5 being the major ones. The isoforms showing concomitant increase with the total enzyme activity were SOD3 and SOD4 in the root and SOD1 and SOD5 in the shoot (Fig. 2). Isoform SOD2, which is expressed only in the cellular space of freeze-stressed barley leaves (Baek et al., 2000), was expressed a little in the saline-stressed leaves, indicating stress-specific expression of barley SOD2 isoform. 


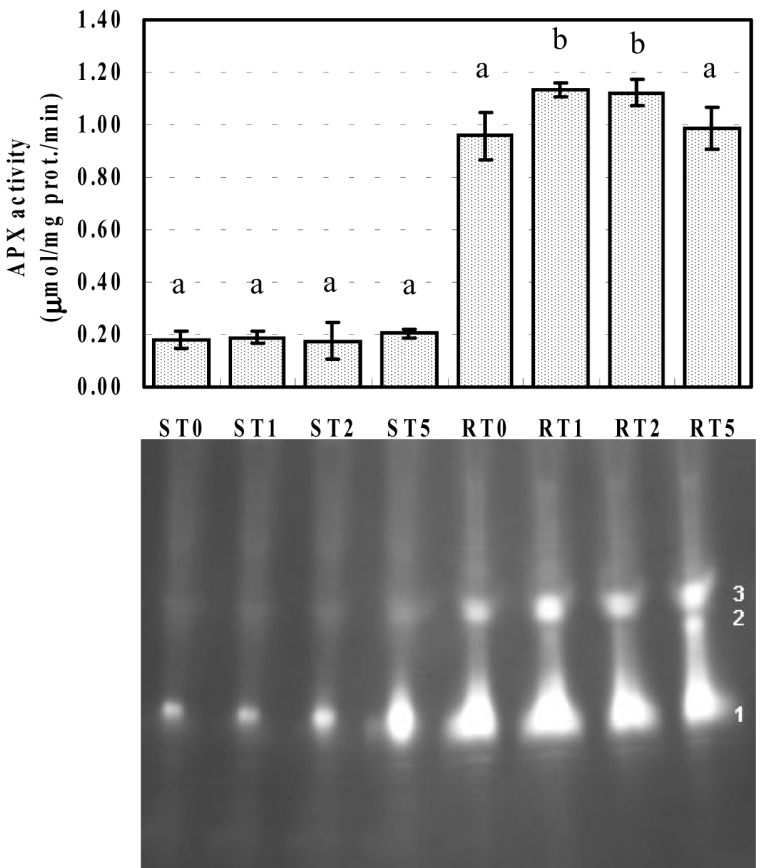

Fig. 4. The responses of APX activities and isoforms in the $\mathrm{NaCl}$-treated barley shoots (ST) and roots (RT). Barley seedlings at the $3^{\text {rd }}$ leaf stage were treated with $200 \mathrm{mM} \mathrm{NaCl}$ for $0,1,2$ and $5 \mathrm{~d}$, respectively. The treatments indicated by the same letters are not significantly different $(p \leq 0.05)$ within the tissue. APX isoforms were detected on nondenaturing polyacrylamide gels (7\% acrylamide, 3\% bis-acrylamide) containing $10 \%$ glycerol according to Mittler and Zilinskas (1993).

Catalase The specific CAT activity was increased in the root and shoot by the $\mathrm{NaCl}$ treatment. In the root, CAT activity was increased drastically from 1 DAT, reaching to about a $316 \%$ increase at 5 DAT. In the shoot, the activity was increased by about $31 \% 1$ DAT and the increase was reduced by about $20 \%$ by 5 DAT. The activity in the shoot was about five-times higher than that in the root (Fig. 3).

Two or three isoforms were detected in the root and shoot with CAT1 and CAT2 as the major ones in the root and shoot, respectively. In the root, CAT1 expression was increased consistently from 1 to 5 DAT, while CAT2 expression was only at 5 DAT. In the shoot, CAT1 was induced upon the $\mathrm{NaCl}$ treatment and its expression was increased with treatment time, as was the expression of CAT2 and CAT3 (Fig. 3).

Ascorbate peroxidase The specific APX activity was only increased significantly in the root at 1 and 3 DAT. In the shoot, APX activity was slightly increased only at 5 DAT but with no statistical significance. The activity in the root was about fivetimes higher than that in the shoot (Fig. 4).

Two and three isoforms were detected in the root and shoot with APX1 as a major one. In the root, the APX1 and APX3 expression showed a concomitant increase with the total APX activity. APX2 expression was induced at 5 DAT only in the

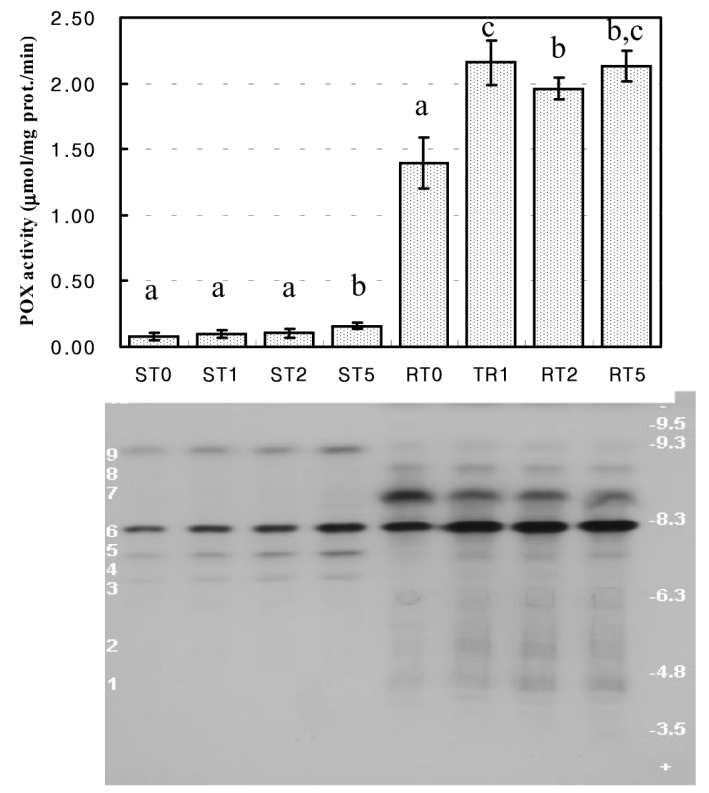

Fig. 5. The responses of $P O X$ activities and isoforms in the NaCl-treated barley shoots (ST) and roots (RT). Barley seedlings at the $3^{\text {rd }}$ leaf stage were treated with $200 \mathrm{mM} \mathrm{NaCl}$ for $0,1,2$ and $5 \mathrm{~d}$, respectively. The treatments indicated by the same letters are not significantly different $(p \leq 0.05)$ within the tissue. POX isoforms were detected on ultrathin-layer IEF gels according to Wendel (1987).

root. A slight increase in APX activity in the shoot coincided with an increase in the APX1 expression (Fig. 4).

Non-specific peroxide The specific POX activity was increased significantly in the root and shoot by $\mathrm{NaCl}$ treatment. In the root, the activity was increased by about $50 \%$ from 1 DAT to 5 DAT. In the shoot, the activity was increased by about $25 \%$ at 1 and 3 DAT and by about $100 \%$ at 5 DAT. The activity in the root was about 18-times higher than that in the shoot (Fig. 5).

At least ten POX isoforms were detected with POX6 as a major one. Increase in root enzyme activity coincided with the increased expression of POX6. Increase in shoot enzyme activity correlated with the enhanced expression of POX5, POX6, and POX9 (Fig. 5). The neutral and basic POX isoforms expressed in saline-stressed leaves are also expressed in the freeze-stressed leaves, but the major isoform POX6 in the saline-stressed leaves is only a minor isoform in the freeze-stressed leaves (Baek et al., 2000). This indicates a difference in the quantitative isoform expression patterns in the two stresses.

Glutathione reductase GR activity was only increased significantly in the root in response to the $\mathrm{NaCl}$ treatment. The activity was increased by about $47 \%$ at 1 DAT, and was maintained at the increased levels until 5 DAT. The activity in the root was about three-times higher than that in the shoot (Fig. 6). 

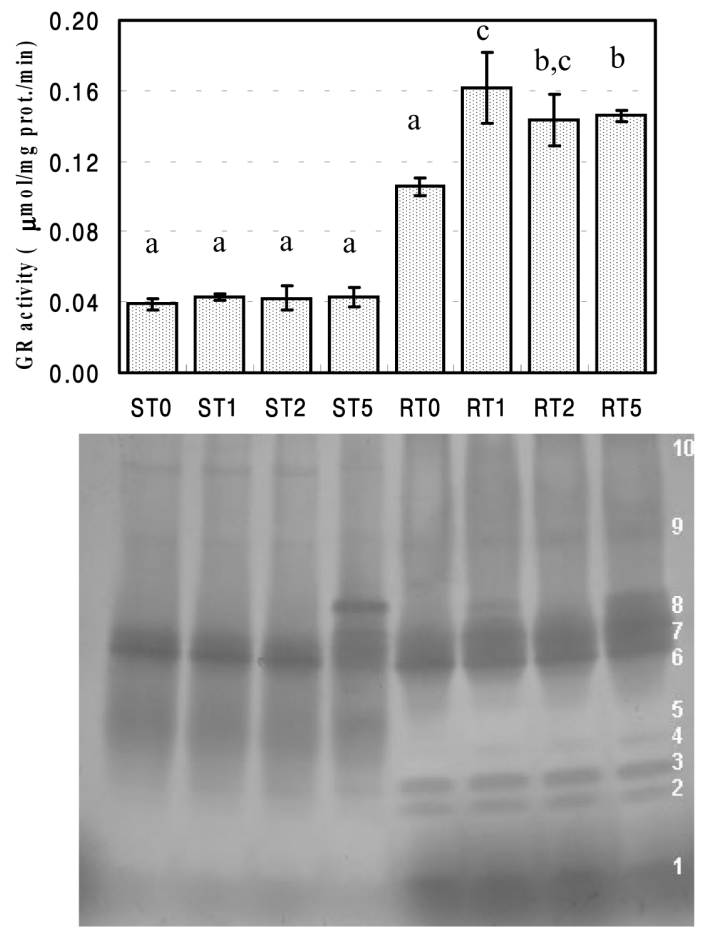

Fig. 6. The responses of GR activities and isoforms in the NaCltreated barley shoots (ST) and roots (RT). Barley seedlings at the $3^{\text {rd }}$ leaf stage were treated with $200 \mathrm{mM} \mathrm{NaCl}$ for $0,1,2$ and 5 $\mathrm{d}$, respectively. The treatments indicated by the same letters are not significantly different $(p \leq 0.05)$ within the tissue. GR isoforms were detected on nondenaturing polyacrylamide gels (7\% acrylamide, 3\% bis-acrylamide) containing $10 \%$ glycerol according to Anderson et al. (1995).

A total of ten GR isoforms were detected with GR6 as the major one. Increase in root enzyme activity coincided with the increased expression of GR7 and GR8. In the shoot, the expression of GR8 was induced, but that of GR6 was suppressed at 5 DAT (Fig. 6).

\section{Discussion}

The activities of barley antioxidant enzymes were increased in the root and shoot under the $\mathrm{NaCl}$ stress. But the increase was more significant and consistent in the root. The activities of SOD, CAT, APX, POX, and GR were increased significantly in the root within $24 \mathrm{hs}$ of the $\mathrm{NaCl}$ treatment, indicating rapid responses of antioxidant enzymes to salt stress in barley roots (Figs. 2, 3, 4, 5, and 6). The increased antioxidant enzyme activities were correlated with decreased hydrogen peroxide in the salt-stressed roots (Fig. 1). Among the enzymes, CAT showed the highest negative relation with hydrogen peroxide content. In glycophytes, the root is the primary site of salt stress and the ability to maintain ion homeostasis and redox potential is critical for the normal root growth and function under saline stress, and often related to salinity resistance
(Greenway and Munns, 1980; Hasegawa et al., 2000). The observations also strongly imply a possibility that antioxidant enzyme systems are also utilized in barley to alleviate oxidative stress caused by salinity, thus protecting the cells from oxidative damage. Detoxification of excess ROS produced during stress is important to reduce ROS-induced membrane lipid peroxidation, enzyme inhibition, and nucleic acid damage (Mittler, 2002). Enzymatic scavenging of ROS could be efficiently achieved through the complex, but elaborate coordination among the enzymes involved (Foyer $e t$ al., 1994; Foyer and Noctor, 2000; Apel and Hirt, 2004). The increased activities of the antioxidant enzymes upon salt stress are often related to the enhanced tolerance to salt stress (Gueta-Dahan et al., 1997; Mittova et al, 2004). Thus, the highest negative correlation of the CAT with hydrogen peroxide content in the salt-stressed root suggests an increased role of CAT in hydrogen peroxide detoxification under salt stress.

Furthermore, each enzyme showed specific quantitative and qualitative responses under salt stress. The major ROSscavenging mechanisms of plants include SOD, APX and CAT (Mittler, 2002). Increase of APX activity was relatively low compared with that of SOD and CAT in the NaCl-treated barley root (Figs. 2, 3 and 4). A rapid and continued increase in CAT activity might indicate that CAT is a major enzyme detoxifying hydrogen peroxide in barley under salt stress. Since ROS are produced through the multiple pathways including the SOD reaction under salt stress, over 2-fold higher increase in CAT activity than in SOD could better contribute in maintaining steady-state levels of cellular hydrogen peroxide. Also, direct evidence from CAT-deficient mutant barley demonstrates the essential role of CAT in stress resistance of barley. The CAT-deficient barley plants develop severe necrotic lesions and barely survive field stress conditions (Acevedo et al., 2001).

The utilization of multiple isoforms of enzymes is one of the primary control mechanisms of cellular metabolism in plants. However, little data is available on the regulation of antioxidant enzymes isoforms expression under salt stress (Gueta-Dahan et al., 1997). Therefore, the isoform specific responses of antioxidant enzymes to salt stress in barley deserve to have a considerable significance. The temporal increase of constitutive isoforms was generally observed in SOD, CAT, POX, and GR in the NaCl-treated barley root and shoot (Figs. 2, 3, 5, and 6). However, the temporal decrease of a specific isoform was only observed in POX in the root. Moreover, the induction of new isoforms was also observed in CAT in the shoot, APX in the root, and GR in the root and shoot, respectively (Figs. 3, 4, and 6). Freezing stress also induces drastic changes in the temporal and spatial expression of antioxidant isoforms in overwintering barley leaves (Baek et al, 2000). The limited success with the single gene transgenic approach to improve abiotic stress tolerance via enhancing antioxidant enzyme capacity indicates the significance of fine-tuning temporal and spatial regulation of 
isoform expression (Bohnert and Sheveleva, 1998; Smimoff, 1998).

In summary, the significant increase in the activities of SOD, CAT, APX, POX, and GR in the NaCl-stressed barley root was highly correlated with the temporal regulation of the constitutive isoforms as well as the induction of new isoforms. Together with a relative importance of CAT in hydrogen peroxide detoxification, the results suggest the significance of temporal and spatial regulation of each antioxidant isoform in determining the competence of the antioxidant enzyme capacity under oxidative stress.

Acknowledgments This work was supported by a grant from the BioGreen 21 Program, Rural Development Administration, Republic of Korea. S. Y. Kim was supported by a grant from the Postdoctoral Program of Chonbuk National University (20022003).

\section{References}

Acevedo A., Paleo A. D. and Federico M. L. (2001) Catalase deficiency reduces survival and pleiotropically affects agronomic performance in field-grown barley progeny. Plant Sci. 160, 847-855.

Anderson, M. D., Prasad, T. K. and Stewart, C. R. (1995) Chang in isozyme profiles of catalase, peroxidase, and glutathione reductase during acclimation to chilling in mesocotyls of maize seedlings. Plant Physiol. 109, 1247-1257.

Apel, K. and Hirt, H. (2004) Reactive oxygen species: Metabolism, oxidative stress, and signal transduction. Аnпи. Rev. Plant Biol. 55, 373-399.

Baek, S. H., Kwon, I. S., Park T. I., Yun, S. J., Kim, J. K. and Choi, K. G. (2000) Activities and isozyme profiles of antioxidant enzymes in intercellular compartment of overwintering barley leaves. J. Biochem. Mol. Biol. 33, 385390.

Beauchamp, C. and Fridovich, I. (1971) Superoxide dismutase: improved assays and an assay applicable to acrlyamide gels. Anal. Biochem. 44, 276-287.

Beers, R. F. and Sizer, I. W. (1952) A spectrophotometric method for measuring the breakdown of hydrogen peroxide by catalase. J. Biol. Chem. 195, 133-140.

Bohnert, H. J. and Sheveleva, E. (1998) Plant stress adaptationsmaking metabolism move. Curr. Opin. Plant Biol. 1, 267-274.

Bradford, M. M. (1979) A rapid and sensitive method for the quantitation of microgram quantities of protein utilizing the principle of protein-dye binding. Anal. Biochem. 72, 248-254.

Chance, B. and Maehly, A. C. (1955) Assay of catalase and peroxidase. Methods Enzymol. 2, 764-775.

Choi, D. G., Yoo, N. H., Yu, C. Y., de los Reyes, B. and Yun, S. J. (2004) The activities of antioxidant enzymes in response to oxidative stresses and hormones in paraquat-tolerant Rehmannia glutinosa plants. J. Biochem. Mol. Biol. 37, 618624.

Dionisio-Sese, M. L. and Tobita, S. (1998) Antioxidant responses of rice seedlings to salinity stress. Plant Sci. 135, 1-9.

Fedina, I. S., Grigorova, I. D. and Georgieva, K. M. (2003)
Response of barley seedlings to UV-B radiation as affected by NaCl. J. Plant Physiol. 160, 205-208.

Foyer, C. H. and Noctor, G. (2000) Oxygen processing in photosynthesis: regulation and signaling. New Phytol. 146, 359388.

Foyer, C., Descourvieres, P. and Kunert, K. J. (1994) Protection against oxygen radicals: an important defense mechanism studied in transgenic plants. Plant Cell Environ. 17, 507-523.

Greenway, H. and Munns, H. (1980) Mechanisms of salt tolerance in nonhalophytes. Annu. Rev. Plant Physiol. 31, 149-190.

Gueta-Dahan, Y., Yaniv, Z., Zilinskas, B. A. and Ben-Hayyim, G. (1997) Salt and oxidative stress: similar and specific responses and their relation to salt tolerance in citrus. Planta 203, 460469.

Hasegawa, P. M., Bressan, R. A., Zhu, J. K. and Bohnert, H. (2000) Plant cellular and molecular responses to high salinity. Annu. Rev. Plant Mol. Biol. 51, 463-499.

Kang, J. H. (2004) Modification of Cu,Zn-superoxide dismutase by oxidized catecholamines. J. Biochem. Mol. Biol. 37, 325329.

Mittler, R. (2002) Oxidative stress, antioxidants and stress tolerance. Trends Plant Sci. 7, 405-410.

Mittler, R. and Zilinskas, B. A. (1993) Detection of ascorbate peroxidase activity in native gels by inhibition of the ascorbatedependent reduction of nitroblue tetrazolium. Anal Biochem. 212, 540-546.

Mittova, V., Guy, M., Tal, M. and Volokita, M. (2004) Salinity upregulates the antioxidative system in root mitochondria and peroxisomes of the wild salt-tolerant tomato species Lycopersicon pennellii. J. Exp. Bot. 55, 1105-1113.

Mukherjee, S. P. and Choudhari M. A. (1983) Implications of water stress induced changes in the levels of endogenous ascorbic acid and hydrogen peroxide in Vigna seedlings. Physiol. Plant. 58, 116-170.

Nakano, Y. and Asada, K. (1981) Hydrogen peroxide is scavenged by ascorbate-specific peroxidase in spinach chloroplasts. Plant Cell Physiol. 22, 867-880.

O'Kane, D., Gill, V., Boyd, P. and Burdon, R. (1996) Chilling, oxidative stress and antioxidant responses in Arabidopsis thaliana callus. Planta 198, 371-377.

Oberley, L. W. and Spitz, D. R. (1984) Assay of superoxide dismutase activity in tumor tissue. Methods Enzymol. 105, 457464.

Park, M. E., Choi, H. R., Choi, J. S., Kim, J. G., Suh, S. J., Kang, H. J., Kim, C. K., Choi, K. G. and Yun, S. J. (2003) Growth characteristics of barley seedlings in hydroponic culture conditioned artificial wet injury. Kor. J. Crop Sci. 48, 160-168.

Sairam, R. K., Rao, V. K., and Srivastava, G. C. (2002) Differential response of wheat genotypes to long term salinity stress in relation to oxidative stress, antioxidant activity and osmolyte concentration. Plant Sci. 163, 1037-1046.

Smimoff, N. (1995) Antioxidant systems and plant response to the environment; in Environment and Plant Metabolism, Smimoff, N. (ed.), pp 217-243, Bios Scientific Publishers, Oxford, United Kingdom.

Smimoff, N. (1998) Plant resistance to environmental stress. Curr. Opin. Biotechnol. 9, 214-219.

Torsethaugen, G., Pitcher, L. H., Zilinskas, B. A. and Pell, E. J. (1997) Overproduction of ascorbate peroxidase in the tobacco chloroplast does not provide protection against ozone. Plant 
Physiol. 114, 529-537.

Van Camp, W., Capiau, K., Van Montagu, M., Inze, D. and Slooten, L. (1996) Enhancement of oxidative stress tolerance in transgenic tobacco plants overproducing Fe-superoxide dismutase in chloroplasts. Plant Physiol. 112, 1703-1714.

Wendel, J. F. (1987) Visualization and interpretation of plant isozymes; in Isozymes in Plant Biology, Solitis, D. E and Solitis, P. S. (eds.), pp 5-45, Dioscoridges Press, Portland,
USA.

Willekens, H., Chamnongpol, S., Davey, M., Schraudner, M., Langebartels, C., Van Montagu, M. and Van Camp, W. (1997) Catalase is a sink for $\mathrm{H}_{2} \mathrm{O}_{2}$ and is indispensable for stress defense in C-3 plants. EMBO J. 16, 4806-4816.

Woodbury, W., Spencer, A. K. and Stahmann, M. A. (1971) An improved procedure using ferricyanide for detecting catalase isozymes. Anal. Biochem. 44, 301-305. 